\title{
Non adherence to inhalational medications and associated factors among patients with asthma in a referral hospital in Ethiopia, using validated tool TAI
}

\author{
Asnakew Achaw Ayele* and Henok Getachew Tegegn
}

\begin{abstract}
Background: Asthma is a chronic inflammatory condition of the airways that affects roughly 358 million people globally. It is a serious global health problem with an increasing prevalence worldwide. Most people affected are in low- and middle-income countries including Ethiopia. The association between non-adherence and poor disease control is clearly stated in different literatures. The main objective of the present study was to assess self-reported non- adherence level and to identify the potential factors associated with non-adherence.

Methods: An institution based cross-sectional study was conducted in university of Gondar teaching and referral hospital. The data was collected using a validated tool called Test of Adherence to Inhalers (TAI).

Result: Among the total of study participants, higher proportions of patients were female (57.3\%). Large number of the respondents (59.1\%) were Unable to read and write. 18.3\% of inhalational user asthmatic patients were not adherent to inhalational medications. According to this study only $49.4 \%$ of the respondents were adherent to inhalations and 32. $3 \%$ of them were intermediate adherent to inhalational anti asthmatics medications. Lack of education about the Proper use of inhalational anti-asthmatics medications, poly pharmacy and co-morbidities were statistically significant factors associated with non-adherence.

Conclusion: The rate of non-adherence to inhalational anti asthmatics is high. Therefore, promoting optimal medication adherences through education, proper patient consultation is essential to optimize the benefits of treatment. Measurement of the degree of non-adherence to inhaled treatment in each individual patient is important in early interventional practice.
\end{abstract}

Keywords: Non adherence, Inhalational, Asthma, Gondar, Ethiopia

\section{Background}

Asthma is a chronic inflammatory condition of the airways that affects roughly 358 million people [1]. It is a serious global health problem with an increasing prevalence worldwide. Most people affected are in low- and middleincome countries, and its prevalence is estimated to be increasing fastest in those countries. People of all ages are affected by this chronic airways disorder with higher burden of disability [2]. In 2015, more than 397,100 deaths is caused by asthma and most of which occurred in the

\footnotetext{
* Correspondence: asnake.21.uog@gmail.com

Department of Clinical Pharmacy, School of Pharmacy, College of Medicine and Health Sciences, University of Gondar, P.O.Box: 196, Gondar, Ethiopia
}

developing world [3]. In Ethiopia Asthma deaths reached $0.89 \%$ of total deaths. Asthma is thought to be caused by a combination of both genetic and environmental factors. Symptoms can be prevented by avoiding triggers, such as allergens and irritants. While there is no cure for asthma, symptoms can be improved with combination of medications and avoiding triggering factors. Short-acting beta 2 agonists are the first line treatment for acute asthma symptoms and anticholinergic medications provide additional benefit when used in combination with Short acting beta 2 agonists [4]. Currently corticosteroids are the most effective treatment available for long-term control of asthma [5]. Except in the case of severe persistent disease, 
I-inhaled forms of corticosteroids are usually used in the long term management [5]. Good level of adherence is the cornerstone in the long term management of asthma. In chronic asthmatic patients, non-adherence or inhaler mishandling increases mortality, morbidity, and hospital admission [6, 7].

The association between non -adherence and poor disease control is clearly stated in different literatures. Patient age, level of education/knowledge about the conditions, medication and lack of technical skill of delivery devices were taught to be the cause of nonadherence to inhaled medications [8-11]. In addition to this, complexity of the inhalation regimen, peculiarities of inhaler devices, type of inhaled agent, and a variety of patient beliefs and sociocultural and psychological factors also the cause poor adherence to inhalational medications. [12]. It is important to know that the rational use of inhaled medication improves the outcomes of chronic asthma managements. Among patients receiving long-term pharmacotherapy for chronic diseases, only $50 \%$ of them are adherent to treatment while adherence rates in asthma have been shown to vary widely from $22 \%$ to $78 \%$ [13-16]. Different studies have been published regarding in measuring of non-adherence rate in inhaled medications using standardized Patient selfcompleted questionnaires. Because they are not adequately validated, they become nonspecific for inhaled medications which results in invariably underestimates the incidence of non-adherence rates. The main aim of the present study was to assess self-reported non adherence level and to identify the potential factors associated with nonadherence, using a validated tool called Test of Adherence to Inhalers (TAI) [17].

\section{Methods study design and setting}

An institution based cross-sectional study was conducted in university of Gondar teaching and referral hospital (UoGTRH) from September 2016 to December 2016.

\section{Data collection instrument}

The data was collected using a tool called Test of Adherence to Inhalers (TAI), which is validated in 2016 by PLAZA et al. [17] to assess the level of adherence to inhalers in asthma and COPD patients. TAI consists of both 10 and 12 item questions. The 10- items TAI was designed to identify non-adherent patients and to measure the non-adherence level, whereas the 12-items TAI was designed to guide clinically the non-adherence patterns. TAI scores 50, 46-49 and less than 45 was considered as adherent, intermediate adherent and nonadherent respectively. In the present study the 10 item TAI is used to measure the level of non-adherence. In addition to TAI tool, patients demographics and clinical data was collected. Poly pharmacy is operationally defined as-patients who are taking more than four drugs and co-morbidity is considered if a patients have more than 1 confirmed diagnosis. The questionnaires were initially translated to Amharic (national language of Ethiopia) and then back to English in order to ensure that the translated version gives proper meaning.

\section{Patients' recruitment}

Patients greater than 18 years of age and those who uses inhaled medications for at least 2 years before enrolment were included in the study. Study participants were consecutively enrolled from September 2016 to December, 2016 when they visit Gondar university hospital outpatient pharmacy for refill. The data was collected by pharmacists who have been working in the outpatient pharmacy. TAI is self-compiled questionnaire but for patients who are unable to read and write, the data collectors helped them into the completion of the questionnaire through interview.

\section{Data entry and analysis}

The data was entered to and analyzed using IBM SPSS Statistics for Windows, version 20. Continuous variables were presented as mean \pm standard deviation. Categorical variables were expressed as frequencies and percentages. Association between predictive variables (sociodemographic and clinical data of patients) and dependent variables (non -adherence) using binary logistic regression was done to identify determinants of non-adherence. Variable with $p$ value $<0.20$ were included in the multivariate model and $P$-value less than 0.05 and 95\%, confidence interval $(\mathrm{CI})$ were used as cut off points for determining statistical significance of associations among different variables.

\section{Ethical consideration}

Ethical approval was obtained from research and ethics review committee of school of Pharmacy, University of Gondar to conduct the study. Informed verbal consent was also obtained from each respondent after explaining the purpose of the study. They were also informed that participation was voluntary and they could withdraw from the study at any stage if they desired. Participant's confidentiality was guaranteed by not recording their personal identifiers on the questionnaire.

\section{Result}

Socio demographics and clinical data of the participants A total of 164 asthmatic patients who meets the inclusion criteria were included in the study. Among the total of study participants, higher proportions of patients were female (57.3\%) (Table 1). Most of the participants (47\%) were in between 18 and 30 age group. Large number of the respondents, 97 (59.1\%) were unable to read and 
Table 1 Socio-demographic characteristics of the respondentUOGTRH, 2016

\begin{tabular}{|c|c|}
\hline Patient characteristics and clinical data & $\mathrm{N}(\%)$ \\
\hline Total number of study population, $\mathrm{N}$ & 164 \\
\hline \multicolumn{2}{|l|}{ Sex } \\
\hline Male, n (\%) & $70(42.7)$ \\
\hline Female, n (\%) & $94(57.3)$ \\
\hline \multicolumn{2}{|l|}{ Age } \\
\hline $18-30, n(\%)$ & $(77,47)$ \\
\hline $31-45, \mathrm{n}(\%)$ & $(56,34)$ \\
\hline $46-64, \mathrm{n}(\%)$ & $(18,11)$ \\
\hline$>65, \mathrm{n}(\%)$ & $(13,7.9)$ \\
\hline \multicolumn{2}{|l|}{ Education level } \\
\hline Unable to read and write, $\mathrm{n}(\%)$ & 9759.1 \\
\hline Primary education, n (\%) & 3118.9 \\
\hline Secondary education n (\%) & 2917.7 \\
\hline Higher education, n (\%) & 74.3 \\
\hline \multicolumn{2}{|l|}{ Patient's clinical data, n (\%) } \\
\hline \multicolumn{2}{|l|}{ Previous history of ADR } \\
\hline Yes, n (\%) & $31(18.9)$ \\
\hline No, n (\%) & $133(81.1)$ \\
\hline Duration of disease, years mean (SD) & $6.09+3.13$ \\
\hline \multicolumn{2}{|l|}{ Previous inhaler education } \\
\hline Yes, n (\%) & $52(81.1)$ \\
\hline No, n (\%) & $112(19)$ \\
\hline \multicolumn{2}{|l|}{ Smoking history } \\
\hline Yes, n (\%) & $11(6.7)$ \\
\hline No, n (\%) & $153(93.3)$ \\
\hline \multicolumn{2}{|l|}{ Poly pharmacy } \\
\hline Present & $47(28.6)$ \\
\hline Absent & $117(71.4)$ \\
\hline \multicolumn{2}{|l|}{ Co-morbidity } \\
\hline Yes & $64(39.1)$ \\
\hline No & $100(60.9)$ \\
\hline \multicolumn{2}{|l|}{ Adherence level } \\
\hline Adherent (TAl score $\geq 50), n$ (\%) & $81(49.4)$ \\
\hline Intermediate adherent (TAI score 46-49), n (\%) & $53(32.3)$ \\
\hline Non-adherent (TAl score $\leq 45$ ), n (\%) & $30(18.3)$ \\
\hline
\end{tabular}

write. A total of $18.9 \%$ patients had previous history of adverse drug reaction (ADR) to inhalational anti asthmatic medications. The mean ( \pm standard deviation) duration of years living with the disease was $6.09 \pm 3.13$ ranging from 2 to 19 years. Respondents who were not taking inhaler education was found to be $18.9 \%$, whereas $6.7 \%$ were smokers as shown in Table 1.

Among the total participants, ploy pharmacy was present in $28.6 \%$ of them. Regarding to co-morbidity, $39.1 \%$ of the participants has had at least one more disease in addition to asthma. Table 1 Details of sociodemographic data of the participants.

\section{Non adherence level to inhalational anti- asthmatics medications}

The level of adherence to inhalers among the participants was assessed using 10- items TAI tool. According to this study $49.4 \%$ of the respondents were adherent to inhalations with TAI score greater than 50 and $32.3 \%$ of them (TAI score 46-49) were intermediate adherent to inhalational anti asthmatics medications. However the result of this study reveals that $18.3 \%$ of asthmatic patients (TAI score $\leq 45$ ) were not adherent to inhalational anti asthmatics medications. Response of the TAI questions of the respondents is summarized in Table 2 .

In Multivariate logistic regression analysis, respondents who had not received education about inhalational use were about 8 times more likely to be non-adherent compared to those who had received $(\mathrm{AOR}=8.14,95 \%$ CI, 1.27, 47.29)(Table 3). Respondents who have experienced ADR to inhalational anti-asthmatics previously were more likely to be non-adherent. The presence of co-morbidity was associated with increased nonadherence to inhalational medications $(\mathrm{AOR}=4.6095 \%$ CI, 2.39, 12.945). The occurrence of non-adherence to inhalational medications was 6 times more likely among patients with poly pharmacy $(\mathrm{AOR}=6.488(95 \% \mathrm{CI}, 3.31$, 15.77). Patients who had no formal education were 2.71 times more likely to being non adherent to their medications than those who attended higher education $(\mathrm{AOR}=2.71(95 \% \mathrm{CI}, 1.62,7.66)$. However other characteristics (age group and sex) were not significantly associated with non-adherence to inhalational medications.

\section{Discussion}

To our best knowledge, non-adherence of asthmatic patients to inhalational medications was scarcely investigated in Ethiopia. Although there are few published studies, and they have used different methods to assess non adherence of asthmatic patients to treatment, these data lacks the methodology specific to inhalational antasthmatics. This study was held in order to assess the level of non-adherence and to identify factors associated with non-adherence using TAI tool which is specific to inhalational medications. The result of the present study reveals that $49.4 \%$ of the asthmatic patients were adherent and $32.3 \%$ were intermediate adherent to their medications. However the prevalence of non-adherence is 18.3\%. This percentage shows that still many asthmatic patients are not adherent to their inhalational medications. Previously done research shows that, adherence to inhaled therapies is worse than that seen with oral or 
Table 2 Response of the respondents to TAl questionnaires- UOGTRH, 2016

\begin{tabular}{|c|c|c|c|c|c|}
\hline \multirow[t]{2}{*}{ TAl questions } & \multicolumn{5}{|l|}{ TAl scores } \\
\hline & All n (\%) & $\begin{array}{l}\text { More than half } \\
\mathrm{n}(\%)\end{array}$ & $\begin{array}{l}\text { About half } \\
\mathrm{n}(\%)\end{array}$ & $\begin{array}{l}\text { Less than half } \\
\mathrm{n}(\%)\end{array}$ & $\begin{array}{l}\text { None } \\
\mathrm{n}(\%)\end{array}$ \\
\hline \multirow[t]{2}{*}{ How many times did you forget to take your regular inhalers in the last 7 days? } & $6(3.7)$ & $11(6.7)$ & $13(7.9)$ & $18(11.6)$ & $115(70.1)$ \\
\hline & $\begin{array}{l}\text { Always } \\
\mathrm{n}(\%)\end{array}$ & $\begin{array}{l}\text { Almost always } \\
\mathrm{n}(\%)\end{array}$ & $\begin{array}{l}\text { Sometimes } \\
\text { n (\%) }\end{array}$ & $\begin{array}{l}\text { Almost never } \\
\mathrm{n}(\%)\end{array}$ & $\begin{array}{l}\text { Never } \\
\mathrm{n}(\%)\end{array}$ \\
\hline You forget to take your inhalers: & $7(4.3)$ & $10(6.1)$ & $11(6.7)$ & $15(9.1)$ & $121(73.8)$ \\
\hline When you are feeling well, you stop taking your inhalers: & $7(4.3)$ & $13(7.9)$ & $7(4.3)$ & $34(20.7)$ & $103(62.8)$ \\
\hline At the weekend or when you go on holiday, you stop taking your inhalers: & $12(7.3)$ & $8(4.9)$ & $5(3)$ & $18(11)$ & $121(73.8)$ \\
\hline When you are anxious or sad, you stop taking your inhalers: & $4(2.4)$ & $5(3)$ & $12(7.3)$ & $13(7.9)$ & $130(79.3)$ \\
\hline You don't take your inhalers out of fear of potential side effects & $7(4.3)$ & $8(4.9)$ & $15(9.1)$ & $2(1.2)$ & $132(80.5)$ \\
\hline $\begin{array}{l}\text { You stop taking your inhalers because you believe that they are of little help in } \\
\text { treating your disease: }\end{array}$ & $3(1.8)$ & $9(5.5)$ & $14(8.5)$ & $38(13.2)$ & $100(61)$ \\
\hline You take fewer inhalations than prescribed by your doctor: & $6(3.7)$ & $6(3.7)$ & $16(9.8)$ & $39(23.8)$ & $97(59.1)$ \\
\hline $\begin{array}{l}\text { You stop taking your inhalers because you believe that they interfere with your } \\
\text { day-to-day or work life: }\end{array}$ & $4(2.4)$ & $7(4.3)$ & $11(6.7)$ & $44(26.8)$ & $98(59.8)$ \\
\hline You stop taking your inhalers because you have trouble paying for them: & $11(6.7)$ & $6(3.7)$ & $7(4.3)$ & $26(15.9)$ & $114(69.5)$ \\
\hline
\end{tabular}

Table 3 Patient's clinical and demographic data associated with non-adherence-

\begin{tabular}{|c|c|c|c|c|c|}
\hline \multirow[t]{2}{*}{ Variables } & \multicolumn{2}{|c|}{ Non - adherence } & \multicolumn{2}{|l|}{ OR $(95 \% \mathrm{Cl})$} & \multirow[t]{2}{*}{$P$-value } \\
\hline & Yes & No & $\overline{C O R}$ & AOR & \\
\hline \multicolumn{6}{|l|}{ Age } \\
\hline $18-30$ & 5 & 72 & 1 & 1 & - \\
\hline $31-45$ & 6 & 50 & $0.769(0.39-1.52)$ & $0.83(0.35,1.97)$ & 0.671 \\
\hline $46-64$ & 7 & 11 & $0.79(0.27-2.30)$ & $1.39(0.20-9.56)$ & 0.545 \\
\hline$>65$ & 10 & 3 & $1.24(0.28-5.34)$ & $1.38(0.18-10.22)$ & 0.432 \\
\hline \multicolumn{6}{|l|}{ Education level } \\
\hline Unable to read and write & 23 & 74 & $1.8(0.92-3.24)$ & $2.71(1.62,7.66)^{\mathrm{a}}$ & 0.032 \\
\hline Primary education & 7 & 24 & $2.48(0.37-18.25)$ & $0.08(0.10-0.79)$ & 0.553 \\
\hline Secondary education & 4 & 25 & $0.66(0.11-3.84)$ & $0.38(0.03-4.37)$ & 0.653 \\
\hline Higher education & 2 & 5 & 1 & 1 & - \\
\hline \multicolumn{6}{|l|}{ Patients clinical data } \\
\hline \multicolumn{6}{|l|}{ Previous inhaler education } \\
\hline Yes & 5 & 49 & 1 & 1 & - \\
\hline No & 64 & 48 & $2.24(0.59-8.37)$ & $8.14(1.27,47.29)^{a}$ & 0.002 \\
\hline \multicolumn{6}{|l|}{ Previous history of severe ADR } \\
\hline Yes & 20 & 11 & $6.67(0.61-73.03)$ & $29.87(1.26,708.6)^{a}$ & 0.035 \\
\hline No & 26 & 107 & 1 & 1 & - \\
\hline \multicolumn{6}{|l|}{ Poly pharmacy } \\
\hline Present & 39 & 8 & $2.09(0.88-4.30)$ & $6.488(3.310,15.770)^{a}$ & 0.027 \\
\hline Absent & 28 & 89 & 1 & 1 & - \\
\hline \multicolumn{6}{|l|}{ Co-morbidity } \\
\hline Yes & 44 & 20 & $0.76(0.55,1.03)$ & $4.60(2.39,12.945)^{\mathrm{a}}$ & 0.026 \\
\hline No & 23 & 77 & 1 & 1 & - \\
\hline
\end{tabular}


injected therapies in patients with asthma in different age groups [18-21].

According to study conducted in turkey to assess the effects of training on the correct use of inhalation devices, only $55.3 \%$ of patients were able to correctly use the devices before training but after the training, the rate of correct use increased to $83.7 \%$ [22]. Valid educational programs for asthmatics can improve the knowledge about the disease and to understand how they take their inhalational medications to improve adherence. Patients attending two lessons with helpful training tools significantly increase their knowledge about asthma treatment compliance and patient self-management [23].

Identifying the reasons for non-adherence to inhalational medications is essential in order to determine the best way to intervene and to increase the control of asthma. The result of previously published study shows that age of the patients, knowledge about the disease, lack of skills about delivery devices, regimen complexity of the medication regimen, adverse effects And lack of health education are some of the factors that affects adherence to inhalational medications [24-29]. Higher rates of non-adherence been associated with Inhaler use potentially because of the increased complexity introduced by the inhalers and lack of skills for appropriate use [30, 31]. In our study from a total of patients who had not received education about proper inhalational medication use, $57 \%$ of them are not adherent to their medications. Moreover $18.9 \%$ of the study participants did never receive any instruction to inhaler technique from health care givers and medication dispensers. The Odds of non-adherence for a subject who had not received education about proper inhalational medication use had a very high probability of being non adherent when compared to a subject who had received education (AOR $=8.14$; 95\%CI: 1.27, 47.29).

Result of previous study shows that the major nondrug factors associated with non-adherence is fear about side effects to the medications [26]. The finding of this study reveals that patients with experience of previous ADR were more likely to be non-adherent to their medications. This is due to the fact that patients may not take their medications, if they fear side effects. Efforts to minimize the level of non-adherence to inhalational medications should be made by letting patients know at the start of the treatment which side effects are possible with a given regimen, monitoring for such effects and provide treatment for adverse effects. This can be achieved through pharmacists even from beginning with the first dispensing of inhalational anti asthmatics. Another important issue regarding the factors that affect non-adherence to inhalational medications is that poly pharmacy. In the present study Patients who have taken an average of more than 4 drugs are more likely to become non-adherent. Co-morbidity is also one factor that have negative impact on the outcomes of asthma treatment. In our study patients with co-morbidity is 4.6 is more likely to be non-adherent.

\section{Limitations of the study}

This study tried to assess the level of non- adherence using a self-reported survey, which subjects it to the recall and social desirability biases. The other limitation was that types of ADR, specific comorbidities and types inhalation medications patients had is not addressed. The sample size obtained during the study period is rather small as it has been done in single centered setup.

\section{Conclusion}

The rate of non-adherence to inhalational anti-asthmatics is high. Lack of education about the Proper use of inhalational anti-asthmatics medications, poly pharmacy and co-morbidities have been identified to have affected nonadherence rate. Therefore, promoting optimal medication adherences through education, proper patient consultation essential to optimize the benefits of treatment. Subsequently, measurement of the degree of non-adherence to inhaled treatment in each individual patient becomes increasingly important in early interventional practice.

Acknowledgements
The authors acknowledge the support of University of Gondar and UOGRTH
in facilitating the data collection process.
Funding
This Study has not receive any fund.
Availability of data and materials
The data are available from the corresponding author on reasonable request.

Authors' contributions

All authors are equally contributed. Both authors read and approved the final manuscript.

Ethics approval and consent to participate

This study was approved by the research ethics committee of school of pharmacy, university of Gondar.

Consent for publication

Not applicable.

Competing interests

The authors declare that they have no competing interests.

\section{Publisher's Note}

Springer Nature remains neutral with regard to jurisdictional claims in published maps and institutional affiliations.

Received: 31 July 2017 Accepted: 2 October 2017

Published online: 06 October 2017

Reference

1. Vos T, Barber RM, Bell B, Bertozzi-Villa A, Biryukov S, Bolliger I, Charlson F, Davis A, Degenhardt L, Dicker D, Duan L. Global, regional, and national incidence, prevalence, and years lived with disability for 301 acute and chronic diseases and injuries in 188 countries, 1990-2013: a systematic analysis for the global burden of disease study 2013. Lancet. 2015;386(9995):743. 
2. Van Gemert F, Van der Molen T, Jones R, Chavannes N. The impact of asthma and COPD in sub-Saharan Africa. Prim Care Respir J. 2011;20:240-8.

3. Sharma S, Shrama R, Sharma M, Verma M. Association between Bronchial asthma and Allergic Rhinitis: A Cross-sectional Study. International Multispecialty Journal of Health. 2016;2:32-37

4. Parsons JP, Hallstrand TS, Mastronarde JG, Kaminsky DA, Rundell KW, Hull JH, Storms WW, Weiler JM, Cheek FM, Wilson KC, Anderson SD. An official American Thoracic Society clinical practice guideline: exercise-induced bronchoconstriction. Am J Respir Crit Care Med. 2013;187(9):1016-27.

5. E B, Hurd SS, Barnes PJ, Bousquet J, Drazen JM, FitzGerald M, Gibson P, Ohta K, O'byrne P, Pedersen SE, Pizzichini E. Global strategy for asthma management and prevention: GINA executive summary. Eur Respir J. 2008; 31(1):143-78.

6. Melani AS, Bonavia M, Cilenti V, Cinti C, Lodi M, Martucci P, Serra M, Scichilone N, Sestini P, Aliani M, Neri M. Gruppo Educazionale Associazione Italiana Pneumologi Ospedalieri: inhaler mishandling remains common in real life and is associated with reduced disease control. Respir Med. 2011;105:930-8.

7. Rau JL. Determinants of patient adherence to aerosol regimen. Respir Care. 2005;50:1346-56.

8. Cohen JL, Mann DM, Wisnivesky JP, Home R, Leventhal H, Musumeci-szabo' TJ, Halm EA. Assessing the validity of self-reported medication adherence among inner-city asthmatic adults: the medication adherence report scale for asthma. Ann Allergy Asthma Immunol. 2009;103:325-31.

9. Barnestein-Fonseca P, Leiva-Fernández J, Vidal-España F, García-Ruiz A, Prados-Torres D, Leiva-Fernández F. Efficacy and safety of a multifacto intervention to improve therapeutic adherence in patients with chronic obstructive pulmonary disease (COPD): protocol for the ICEPOC study. Trials. 2011;12(1):40.

10. Gamble J, Stevenson M, McClean E, Heaney LG. The prevalence of nonadherence in difficult asthma. Am J Respir Crit Care Med. 2009;180(9): 817-22.

11. Broder MS, Chang EY, Kamath T, Sapra S. Poor disease control among insured users of high-dose combination therapy for asthma. In: Allergy and asthma proceedings; 2010;31(1):60-67.

12. Cegala DJ, Marinelli T, Post D. The effects of patient communication skills training on compliance. Arch Fam Med. 2000;9(1):57.

13. Cerveri I, Locatelli F, Zoia MC, Corsico A, Accordini S, De Marco R. International variations in asthma treatment compliance the results of the European Community respiratory health survey (ECRHS). Eur Respir J. 1999; 14(2):288-94.

14. Coutts JA, Gibson NA, Paton JY. Measuring compliance with inhaled medication in asthma. Arch Dis Child 1992;67(3):332-3.

15. Bender BG, Pedan A, Varasteh LT. Adherence and persistence with fluticasone propionate/salmeterol combination therapy. J Allergy Clin Immunol. 2006:118(4):899-904.

16. Krigsman K, Nilsson JL, Ring L. Refill adherence for patients with asthma and COPD: comparison of a pharmacy record database with manually collected repeat prescriptions. Pharmacoepidemiol Drug Saf. 2007;16(4):441-8.

17. Plaza V, López-Viña A, Cosio BG. Test of adherence to inhalers. In: Archivos de Bronconeumología (English edition); 2017.

18. Jones C, Santanello NC, Boccuzzi SJ, Wogen J, Strub P, Nelsen LM Adherence to prescribed treatment for asthma: evidence from pharmacy benefits data. J Asthma. 2003;40:93e101.

19. McNally KA, Rohan J, Schluchter M, Riekert KA, Vavrek P, Schmidt A, et al. Adherence to combined montelukast and fluticasone treatment in economically disadvantaged African american youth with asthma. J Asthma. 2009:46:921e7.

20. Fitzpatrick AM, Kir T, Naeher LP, Fuhrman SC, Hahn K, Teague WG. Tablet and inhaled controller medication refill frequencies in children with asthma. J Pediatr Nurs. 2009;24:81e9.

21. Rand C, Bilderback A, Schiller K, Edelman JM, Hustad CM, Zeiger RS, et al. Adherence with montelukast or fluticasone in a long-term clinical trial: results from the mild asthma montelukast versus inhaled corticosteroid trial. J Allergy Clin Immunol. 2007;119:916e23.

22. Aydemir $Y$. Assessment of the factors affecting the failure to use inhaler devices before and after training. Respir Med. 2015;109(4):451-8.

23. Gaude GS, Hattiholi J, Chaudhury A. Role of health education and selfaction plan in improving the drug compliance in bronchial asthma. Journal of family medicine and primary care. 2014;3(1):3.

24. Juniper EF. The impact of patient compliance on effective asthma management. Curr Opin Pulm Med. 2003;9(Suppl1):S8-S10.
25. Sprossmann A, Kutschka F, Enk M, Bergmann KC. Factors affecting correct use of metered dose aerosols. Z Erkr Atmungsorgane. 1991;177(1e2):93e5.

26. Lacasse $Y$, Archibald H, Ernst P, Boulet L-P. Patterns and determinants of compliance with inhaled steroids in adults with asthma. Can Respir J. 2005; 12:211e7.

27. Soriano JB, Rabe KF, Vermeire PA. Predictors of poor asthma control in European adults. J Asthma. 2003;40:803e13.

28. Partridge MR, van der Molen T, Myrseth SE, Busse WW. Attitudes and actions of asthma patients on regular maintenance therapy: the INSPIRE study. BMC Pulm Med. 2006;6:13.

29. D'Amato M, Baiardini I, Solidoro P. Braido F. Adherence to treatment and monitoring tools: what's new? Minerva Med. 2016;07:5-8.

30. Cegala DJ, Marinelli T, Post D. The effects of patient communication skills training on compliance. Arch Fam Med. 2000;9:57-64.

31. Braido F, Chrystyn H, Baiardini I, Bosnic-Anticevich S, van der Molen T, Dandurand RJ, Chisholm A, Carter V, Price D. Respiratory effectiveness group."trying, but failing" - the role of inhaler technique and mode of delivery in respiratory medication adherence. J Allergy Clin Immunol Pract. 2016;4(5):823-32.

\section{Submit your next manuscript to BioMed Central and we will help you at every step:}

- We accept pre-submission inquiries

- Our selector tool helps you to find the most relevant journal

- We provide round the clock customer support

- Convenient online submission

- Thorough peer review

- Inclusion in PubMed and all major indexing services

- Maximum visibility for your research

Submit your manuscript at www.biomedcentral.com/submit
) Biomed Central 